\title{
Sobre a Maneira de Produzir Dados no Estudo da Interação Social ${ }^{1,2}$
}

\author{
Kurt Kreppner ${ }^{3}$ \\ Instituto Max Planck para o Desenvolvimento Humano - Berlim, Alemanha
}

\begin{abstract}
RESUMO - É arguído, neste artigo, que o requisito mais urgente e necessário à pesquisa observacional é a criação de categorias factuais-sensitivas que descrevam detalhes das condições humanas e situacionais específicas das trocas comunicativas. É também arguído que o processo de seleção de itens simples no fluxo de eventos é regulado por teorias e interesses dos observadores. Sem um conjunto preciso de hipóteses, nenhuma categoria pode ser formulada. Entretanto, as categorias devem ser criadas através de uma intensa interação com o material observado e novas categorias, que podem descrever eventos inesperados durante as observações, devem ser permitidas. Uma vez que os registros em vídeo garantem uma preservação da situação original, uma nova e profunda abordagem para gerar categorias é proposta. Tal abordagem abandona o uso restritivo de categorias predefinidas e defende uma abertura e um processo amplo de trocas com o material antes que as abstrações e categorias sejam formuladas.
\end{abstract}

Palavras-chave: metodologia observacional; produção de dados; categorização da interação humana; pesquisa com famílias.

\section{On the Generation of Data in the Study of Social Interaction}

\begin{abstract}
In this article, it is argued that the most urgent and necessary requisite for observational research is the creation of material-sensitive categories which depict details of specific situational and human conditions of exchange. It is also argued that the process of selection of single items in the stream of events is regulated by theories and interests of the observers. Without a precise set of hypotheses, no categories can be formulated. However, categories should be created in intense interaction with the observed material and new categories which can describe unexpected events during observations should be allowed. Since video-recordings guarantee a conservation of the original situation, a new and intense approach for generating categories is proposed which abandons the restrictive use of predefined categories and argues for openness and an extensive process of exchange with the material before abstractions and categories are formulated.
\end{abstract}

Key words: observational methodology; data generation; categorization of human interaction; family research.

\section{Alguns Comentários Pessoais}

Este artigo é a versão revisada de uma contribuição efetuada durante uma atividade pré-congresso da VII Conferência da Sociedade Internacional para o Estudo do Desenvolvimento do Comportamento [ISSBD], realizada em Munique, em 1983. O workshop foi intitulado Metodologia Observacional na Pesquisa em Interação Social: Três Abordagens Teóricas, seus Potenciais e Limites. Os organizadores propuseram três questões: (a) qual é a relação entre teoria e método?, (b) que tipo de metodologia é necessário? e (c) que métodos existem até agora? Durante os últimos anos da

1 Versão revista do artigo baseado em uma apresentação no workshop intitulado Metodologia Observacional na Pesquisa em Interação Social: Três Abordagens Teóricas, seus Potenciais e Limites, realizado em Munique, em 31 de Julho de 1983. Esta revisão foi escrita em 1999/2000. Agradeço à Profa. Dora Dessen, da Universidade de Brasília, que me encorajou a escrever a revisão de um manuscrito quase esquecido. Suas contribuições estimulantes a este tópico, em nossas discussões, e sua paciência infinita com minha resistência em retomar uma velha questão controvertida, levaram-me, finalmente, a redigir esta revisão.

2 Tradução efetuada por Maria Auxiliadora Dessen.

3 Endereço: Max Planck Institute for Human Development, DahlemLentzedlee, 94, D-14195 Berlin, Germany. E.mail: kreppner@mpibberlin.mpg.de década de 70, a pesquisa observacional sobre os primeiros meses de vida e a infância tinha alcançado o seu primeiro pico e, em 1983, ela começou, claramente, a ser aceita como uma metodologia própria para se obter informação sobre a vivacidade e mutualidade nas interações precoces entre os bebês e seus cuidadores. A esta nova metodologia estava associado um corpo crescente de conhecimento sobre as habilidades sociais e a competência cognitiva surpreendente dos bebês.

No entanto, muitos psicólogos sem experiência em pesquisa relativa à infância, uma área que tinha se expandido para um amplo campo interdisciplinar, permaneceram cépticos em relação à utilidade das técnicas de observação do comportamento. Vários princípios científicos pareciam ser ignorados ou negligenciados pelos pesquisadores, tais como a cegueira de observadores para efeitos esperados. Acreditava-se que os eles podiam perder a sua objetividade durante o processo de observação e se tornar seletivos por focalizarem a ocorrência de eventos esperados. Entretanto, a comparação de estudos observacionais com aqueles estritamente experimentais permitiu que este efeito fosse logo esclarecido, não sendo considerado diferente do tão bem conhecido efeito do experimentador descrito por Rosenthal (1966). Além disso, como a utilização do vídeo garantia a preservação da situação tal qual observada e permitia infinitas replicações durante o processo de análise, as afirmações 
sobre a falta de objetividade desse método não puderam ser sustentadas. Outra crítica contra o uso da metodologia observacional estava relacionada ao fato de que observadores muito treinados colocariam em risco uma observação objetiva; portanto, observadores destreinados e "imparciais" deveriam ser usados. Porém, a idéia de um observador imparcial é aparentemente irracional, já que todo sujeito humano percebe o mundo com um conjunto de expectativas. Somente a câmera pode produzir um tipo de protocolo objetivo de uma situação observada.

A partir de uma perspectiva atual, muitas destas demandas tradicionais podem parecer um tanto vazias, já que a tecnologia para conduzir observações mudou, além de ser um tanto diferente das técnicas empregadas durante os anos 60 e começo dos anos 70. A partir de meados dos anos 70, as observações avançadas foram, então, sempre associadas ao uso de gravações em vídeo. A metodologia observacional não era mais associada a observadores que usavam observação direta e, portanto, que efetuavam o registro do que era observado no momento, usando categorias predefinidas. A possibilidade de "congelar" a situação original, isto é, de conservar a totalidade de aspectos contidos em uma situação observada, mudou principalmente o teor da discussão sobre a necessidade de começar a observação com um conjunto de categorias selecionadas. Antes do uso do filme ou vídeo, a complexidade da situação observada deixava de existir quando o observador terminava os registros em seu protocolo. O que permanecia eram os registros dos observadores nos protocolos, indicando a ocorrência de certos comportamentos. Com a nova tecnologia, porém, a existência de um conjunto de categorias selecionadas previamente deixou de ser uma pré-condição necessária para se fazer boas observações. Usando a tecnologia de vídeo, os pesquisadores puderam replicar inteiramente a situação observada sem introduzir qualquer distorção. Além disso, através da possibilidade de passar uma fita de vídeo muitas vezes, os pesquisadores puderam, então, focalizar os diferentes aspectos de uma mesma situação. Portanto, a possibilidade de criar novas categorias adaptadas às situações observadas concretamente emergiu.

A pesquisa observacional adquiriu um proeminente status durante os últimos 25 anos, em várias áreas do desenvolvimento infantil. As dúvidas iniciais sobre o uso da observação como um método científico sério diminuíram consideravelmente. Porém, em outras áreas da psicologia do desenvolvimento, como adolescência e idade adulta, e mais ainda em outras áreas da psicologia, em geral, os argumentos principais contra o uso deste método ainda persistem, impedindo os pesquisadores de usarem apropriadamente este enfoque em seus campos específicos. Para compreender um pouco o contexto da minha contribuição original, eu gostaria de dizer algumas palavras sobre minhas experiências pessoais com pesquisa observacional, por ocasião do workshop realizado em 1983.

Eu fui convidado para esta conferência porque havia acabado de publicar alguns resultados e discutido algumas experiências de um estudo longitudinal no qual havíamos ob- servado um número pequeno de famílias com duas crianças durante os dois primeiros anos de vida da segunda criança (Kreppner, Paulsen \& Schütze, 1981, 1982a, 1982b). Um dos principais objetivos deste estudo era a associação entre aspectos psicológicos e sociológicos do desenvolvimento humano através da observação das continuidades e mudanças da família inteira, durante o período de integração de um novo membro, a segunda criança, dentro da família, exigindo desta uma adaptação às necessidades e habilidades do novo membro, as quais mudam rapidamente. $\mathrm{O}$ foco do estudo estava nas interconexões do desenvolvimento da segunda criança com os padrões de comunicação e interação já estabelecidos dos outros membros da família. O interesse específico era sobre como a família integrava o novo membro e encontrava um novo equilíbrio depois da transição familiar de uma para duas crianças.

Tendo em vista que o foco de nosso estudo era constituído pelas observações efetuadas nas casas de famílias jovens, durante a fase em que os pais passavam pelo processo de socialização e integração de uma nova criança, nossos principais interesses e problemas não foram realmente abordados pelo conjunto de questões dos organizadores do workshop. Nosso principal interesse não era nem o de ligar enfoques metodológicos aos teóricos, nem o de prestar muita atenção à adaptação de metodologias existentes ao nosso alvo, a família em transição. Percebemos que havíamos enfrentado problemas bastante diferentes durante o nosso intenso trabalho observacional nas casas das jovens famílias. No nosso trabalho diário, encontramos uma série de problemas que pareciam pertencer a diferentes classes daqueles formulados pelos organizadores. Nossos problemas estavam relacionados a questões que emergiam muito antes daquelas propostas para discussão. As três perguntas dos organizadores supunham um conjunto bem definido de instrumentos disponíveis para categorizar ou medir os fenômenos observados já no começo de qualquer estudo observacional. Em contraste, nosso principal problema, quando assistindo e tentando entender o que havíamos observado nas famílias e conservado em vídeo, parecia ser muito mais fundamental, ou, em outras palavras, obviamente pertencia a diferentes classes de reflexões. Nosso problema poderia ser descrito como o problema de encontrar categorias adequadas que descrevessem situações interacionais complexas relevantes para crianças que crescem em suas famílias. Como nosso objetivo era acompanhar famílias por um período de tempo mais prolongado, isto é, enquanto elas integravam a sua segunda criança, a descrição de várias ações dos membros familiares e as reações subseqüentes de outros membros, incluindo a especificação destas ações e reações, parecia constituir um primeiro passo razoável em nosso enfoque. Pretendíamos criar categorias que abarcassem aspectos da vida familiar e que caracterizassem as principais diferenças nos padrões interacionais da família. A fim de cobrir um amplo espectro de possíveis variações, diferentes áreas foram consideradas tais como características estruturais e dinâmicas, rotinas de socialização e aspectos das comunicações verbal e não verbal (ver Kreppner, 1991, para maiores detalhes). 


\section{Gerando Dados em Pesquisa Observacional: o Uso da Técnica de Vídeo para Descrever Situações Interacionais Complexas}

Após aproximadamente duas décadas de experiência em pesquisa na área de desenvolvimento, incluindo estudos de famílias, tanto com crianças quanto com adolescentes, alguns dos argumentos mencionados na primeira versão deste artigo, escrita em 1983, puderam ser melhor especificados. Ficou evidenciado que quando efetuamos observações em famílias com filhos adolescentes, as dificuldades em representar aspectos relevantes da qualidade do comportamento e do relacionamento são diferentes daquelas que surgem quando observamos famílias com crianças. No entanto, há muitas questões comuns a ambas.

\section{Conservação em fita de vídeo}

Embora as condições observacionais de pesquisas com crianças e adolescentes possam parecer, à primeira vista, bastante diferentes - observações naturais não estruturadas, em famílias com crianças, e observações estruturadas, com tempo limitado e com controle da constelação de subsistemas familiares, em famílias com adolescentes - esta discussão abordará os problemas que são idênticos às duas áreas. Um dos problemas mais fundamentais e recorrentes em nossa pesquisa observacional era a escolha da representação do fluxo real ${ }^{4}$ do comportamento. Com o uso de técnicas cinematográficas, a escolha das categorias, que descrevem adequadamente os comportamentos, as características pessoais ou a qualidade do relacionamento, pôde ser postergada, já que a situação observada, com todos os seus detalhes, havia sido conservada em vídeo, sem nenhum tipo de abstração. Usando o vídeo, um dos problemas mais eminentes das observações anteriores, isto é, o processo de abstração imediato de uma situação complexa pelo observador, pôde ser eliminado. Como Thiel (1991) colocou:

A invenção de câmeras e microfones tornou possível, para os observadores, conservar objetos sem envolver diretamente seus sistemas cognitivos. Os observadores podem delegar a conservação ao processo técnico que pode realizar sua tarefa de forma icônica, não seletiva e abrangente, superando as habilidades do próprio observador. (p. 185)

Aqui, a situação original pode ser revisada várias vezes, sem nenhuma limitação. Isto é totalmente diferente de uma situação onde um observador, com um conjunto de categorias predeterminadas, tem que decidir, na hora, quais das categorias prévias são apropriadas para descrever o que está sendo observado naquele momento. A idéia de usar a câmera para obter observações conservadas objetivamente remonta a Arnold Gesell (1928), que foi um dos primeiros pesquisadores da área de desenvolvimento humano a enfatizar a ob-

4 A ênfase é da tradutora. servação como o método adequado para estudos de crianças pequenas. Ele argumenta em favor do uso de câmeras como observadores objetivos:

A câmera é, em certo sentido, mais poderosa que o olho psicológico. $O$ olho vivo pode ver, mas não pode gravar. Nem mesmo na arcana visual do cortex mais eidético, as imagens imutavelmente permanentes podem ser armazenadas para referência retrospectiva. Isto é justamente o que a câmera pode fazer para nós. Ela pode fornecer gravações ópticas em série - gravações que não desvanecem com o tempo, nem deformam em decorrência do preconceito, mas que perpetuam com fidelidade imparcial a configuração do evento original. (Gesell, 1928, p. 157)

Havendo situações complexas de interação e comunicação gravadas em filme ou vídeo, os pesquisadores encontram-se em uma situação confortável, que é a de escolher, entre os diferentes enfoques, aquele que produzirá categorias apropriadas para abstração. Uma vez que categorias predeterminadas são obrigatórias no caso de observação direta sem o uso de vídeo, a escolha de categorias pode ser postergada e adaptada às condições específicas encontradas durante as próprias observações, quando a situação total é conservada em filme ou em fita de vídeo. Neste caso, a situação pode ser observada repetidamente e, por exemplo, comparada às outras situações observadas. A escolha de categorias pode ser moldada exatamente de acordo com as especificidades da situação observada. Por exemplo, se uma mãe e uma criança foram observadas em uma interação, a troca de olhares ou ritmos de olhar um para o outro podem ser contados com precisão. Quando pais e adolescentes são observados enquanto discutem um dado assunto impresso em um cartão-estímulo, em uma situação estruturada, a escolha de categorias pode ser orientada na direção de aspectos bastante diferentes da situação diádica anterior. Por exemplo, o manejo da situação pelos parceiros em interação, o uso do estilo lingüístico ou da comunicação não verbal.

\section{Escolha de categorias}

A escolha de categorias deve ser justificada pelo grau de representação próprio do fenômeno sob investigação. A representação de um fenômeno em um equivalente numérico tem que ser tanto única como não ambígua (Suppes \& Zinnes, 1963). Quando esta condição não é encontrada, distorções podem ocorrer, desvalorizando todos os esforços observacionais. Métodos estatísticos, que são tão sofisticados e complexos, nunca corrigem as concepções errôneas no processo de representação e abstração. Sem as associações profundas da concepção teórica e da situação observada concretamente com as categorias selecionadas, as abstrações podem se tornar sem sentido ou, pior ainda, podem ser recortadas da realidade, introduzindo viézes nas observações subseqüentes. Os observadores podem ignorar fenômenos existentes porque eles não se adequam ao conjunto de categorias préselecionadas. 


\section{Barreiras encontradas durante a realização de observações em situação de vida real}

Em nossa própria pesquisa, ao lidarmos com famílias inteiras e suas maneiras de integrar e socializar novos membros em suas condições de vida natural, a escolha da unidade observacional pareceu ser crucial para a seleção posterior de categorias. Em situações não-estruturadas de vida familiar, as condições são muito diferentes das situações manipuladas ou experimentais, onde a realidade é deliberadamente reduzida a um número de variáveis predeterminadas. A representação do comportamento ou das dinâmicas de interação por um conjunto de categorias torna-se uma questão crítica em estudos observacionais porque os pesquisadores são, primeiro, confrontados com a riqueza dos comportamentos humanos em seu contexto natural; depois, com o problema de seleção e abstração; e, finalmente, ao analisar e interpretar seus resultados, com o problema de reconstrução de situações sociais complexas, através da referência à contagem de frequência de categorias pré-selecionadas. Em geral, estas categorias não são talhadas para uma representação detalhada da situação concreta observada. Por exemplo, se as categorias são baseadas em definições comportamentais e orientadas para a pessoa, elas não podem abarcar apropriadamente as dinâmicas interacionais. Além disso, como é o caso na pesquisa em psicologia do desenvolvimento, os instrumentos descritivos qualificando, pelo menos em princípio, continuidades e mudanças em padrões de interação, no decorrer do tempo, são necessários. Assim, a escolha de categorias como intervenção, apoio e punição estariam, provavelmente, mais voltadas para uma pessoa-alvo que para a situação inteira. Obviamente, dirigir a atenção para uma pessoa-alvo pode contribuir para a perda do foco nas dinâmicas familiares e na qualidade de relacionamento. Porém, descrições detalhadas de condições relacionais complexas não podem ser obtidas facilmente; elas podem ser feitas somente depois que um grande número de padrões de interação concretos tenha sido observado em várias situações dentro de uma mesma família e, também, através de diferentes famílias. As mudanças nos modos de comunicação e interação, por sua vez, são melhor reconhecidas se, com a ajuda do videoteipe, a vida diária na família tiver sido contrastada, levando em consideração os diferentes períodos de tempo e estágios evolutivos da criança.

\section{Primeira barreira encontrada por um observador}

No começo de um estudo observacional, a tentativa de encontrar categorias adequadas para descrever padrões complexos de interação diária na família é quase sempre associada a um número de sérias dificuldades. Em primeiro lugar, quando as observações são conduzidas em situações diárias, sem nenhuma categoria predeterminada, muitas barreiras surgem e têm que ser superadas (Kreppner, 1982). Quando a nossa equipe começou a observar famílias inteiras sem usar categorias pré-selecionadas, três barreiras surgiram e nos impediram, por algum tempo, de definir classificações sig- nificativas de interações sociais e padrões recorrentes de comportamento interativo. Estas barreiras surgiram do conhecimento adquirido no dia-a-dia e dos hábitos de percepção dos observadores. Durante nossas primeiras discussões, em que tentavamos encontrar algumas abstrações do que havíamos acabado de observar, nos encontramos atados por focalizar o que acreditávamos ser auto-evidente em uma situação específica, ou trivial e não interessante o suficiente para ser registrada.

Ao observar a vida diária em uma família, os observadores podem ser acometidos pela impressão de que nada importante está acontecendo, as interações parecem ser de nível normativo, os ciclos de ação-reação parecem evidentes, aparentemente não fornecendo informação relevante para o observador. A primeira barreira que é encontrada por observadores que querem formular categorias relevantes para a descrição de situações de "vida real", complexas e não-estruturadas, pode ser chamada de barreira da trivialidade.

Se alguém continua observando as interações do dia-adia em uma família, por um período de tempo mais longo, ou se alguém observa, repetidamente, a situação gravada em vídeo, os padrões recorrentes de interação emergem. As comparações entre diferentes situações observadas na mesma família, ou de situações similares observadas entre diferentes famílias, logo revelam rotinas de comunicação e interação específicas de cada uma. Comportamentos de comunicação únicos podem ser percebidos como pertencentes a seqüências recorrentes encontradas em diferentes ocasiões. Em um experimento de laboratório, uma situação complexa é sempre reduzida a um número de variáveis que devem ser controladas. Idealmente, a redução de variação a uma única variável cria uma situação fácil de ser observada e analisada. Entretanto, tal situação é bastante diferente de uma situação onde a família está sendo observada em sua casa, onde pais e crianças estão conduzindo suas atividades de rotina e onde uma alta validade do contexto ambiental de uma criança em desenvolvimento pode ser encontrada. Enquanto os experimentadores, no laboratório, costumam manipular o ambiente dos sujeitos de acordo com suas próprias crenças, os observadores, nos habitats dos próprios sujeitos, encontram-se em posições bastante diferentes: eles se envolvem mais no ambiente natural de seus sujeitos do que é o caso com pessoas que conduzem experimentos padronizados, no laboratório. Assim, os observadores podem, por um lado, ser mais influenciados por eventos inesperados em seus julgamentos e, por outro lado, podem ser mais expostos a sentimentos de tédio quando confrontados com os chamados eventos triviais e padrões recorrentes de comportamento. Categorias predeterminadas são difíceis de aplicar quando o fluxo de eventos percebidos engloba um grande número de fenômenos que parece ser relevante para o mundo dos sujeitos, mas, obviamente, não se adequa à concepção básica das categorias disponíveis. Muito freqüentemente, a barreira da trivialidade é encontrada por observadores porque suas tentativas para descrever os fenômenos em sua superficialidade, sem nenhuma categoria prévia, não torna, imediatamente, estes eventos relevantes, os quais, por sua vez, poderiam ser inter- 
pretados de acordo com uma concepção teórica bem estabelecida. Em outras palavras, os fenômenos ocorrem na superfície de rituais de interação do dia-a-dia em uma família, mas não mostram, imediatamente, sua possível associação com categorias guiadas por teorias.

Refletindo sobre esta barreira, poderia ser útil mencionar a diferenciação básica, feita por Kurt Lewin (1927), entre categorias de observação denominadas genética-fenomenal e condicional. Ele distinguiu o nível de superfície de categorias, que descreve um grande número de fenômenos tal qual eles se apresentam, do nível profundo de classificações, que caracteriza as estruturas básicas ou as condições que levam (ou mesmo causam) aos comportamentos observados na superfície.

Alguém pode fazer dois tipos diferentes de perguntas em relação aos tópicos de estudo em psicologia, assim como em outras ciências. Alguém pode perguntar sobre as características fenomenais de unidades ou eventos psicológicos, por exemplo, quantos tipos de sentimentos podem ser qualitativamente diferenciados uns dos outros ou quais características descrevem uma experiência de um ato voluntário. Independentemente destas, estão as questões relativas ao porquê, à causa e ao efeito, às inter-relações condicionais-genéticas. Por exemplo, alguém poderia perguntar: quais são as condições em que uma decisão foi tomada e quais são os efeitos psicológicos específicos conseqüentes à esta decisão? A representação de características fenomenais é geralmente caracterizada como "descrição" e a representação de relações causais como “explicação”. (Lewin, 1927, p. 377) (Tradução ${ }^{5}$ do alemão)

Assim, como uma primeira tentativa, os pesquisadores deveriam sempre tentar registrar sequiências de comunicação intrafamiliares e ciclos de ação-reação, ao observarem as interações familiares do dia-a-dia, o que poderia ajudar, ao final, a encontrar um arcabouço categórico mais estruturado, englobando o modo específico da família administrar a vida, no seu dia-a-dia.

\section{Segunda barreira encontrada por um observador}

Entretanto, ao tentar formular um tipo de cenário, com categorias que descrevem uma estrutura específica da família, responsável por padrões recorrentes de interação, o pesquisador encontrará uma nova barreira: a barreira da especificidade. Esta barreira é percebida quando as famílias são comparadas entre si. Confrontado com a tarefa de transferir padrões de interação de uma família para a outra, o observador, infelizmente, é obrigado a perceber que o que parece ser um conjunto apropriado de categorias, descrevendo comportamentos de interação em uma família, não é apropriado para o que é encontrado em outra família. Cada família aparece como uma unidade específica, possuindo padrões recorrentes de interação que são típicos e únicos. Encontrar um conjunto único de padrões que poderia ser usado para descrever mais de uma família é, aparentemente,

5 Nota da tradutora: na versão original do artigo em inglês, esta citação foi traduzida do alemão. uma tarefa complicada. Categorias apropriadas podem ser melhor formuladas quando as condições contextuais específicas à família são consideradas durante o processo de abstração. Porém, desconectadas de um contexto particular, muitas destas categorias começam a perder a sua adequação, pois são usadas como classificações gerais para um número de diferentes famílias.

Quando observamos nossas famílias ao longo do tempo, pudemos superar esta barreira da especificidade, comparando sistematicamente famílias em situações similares. Isto significa que as famílias eram semelhantes, uma vez que elas tinham que realizar tarefas análogas e resolver problemas comuns em suas vidas diárias enquanto socializando suas crianças. Por exemplo, trocando fraldas ou alimentando durante a infância, transmitindo regras e regulações durante o segundo e terceiro anos, ou, mais tarde, durante a adolescência do filho, negociando as demandas crescentes por mais autonomia e responsabilidades. Este conceito de tarefas análogas, que todas as famílias têm que realizar, pode superar esta barreira da especificidade.

\section{Terceira barreira encontrada por um observador}

Sob uma perspectiva do desenvolvimento, podemos afirmar que a terceira barreira é encontrada mesmo que a segunda tenha sido superada. A questão, aqui, refere-se à: como alguém poderia avaliar a relevância de um comportamento observado e categorizado em relação ao desenvolvimento futuro? À primeira vista, nenhuma solução imediata parece possível, mesmo quando o material é intensivamente mostrado em vídeo ou filme. Podemos concluir, a partir de certos conjuntos de padrões de interação, que eles impulsionarão uma criança, dentro da família, em uma ou outra direção de sua trajetória de desenvolvimento? Hoje, em contraste com a época do workshop, no começo dos anos 80, temos uma base mais ampla de conhecimento disponível quando tentamos enfrentar o problema da relevância em desenvolvimento, particularmente no que tange aos padrões comportamentais ou à qualidade do relacionamento na família. As pesquisas mais recentes sobre famílias com crianças pequenas e adolescentes têm mostrado amplamente que, por exemplo, a qualidade do relacionamento entre pais é altamente relevante para o domínio bem ou mal sucedido de transições no desenvolvimento. Erel e Burman (1995) mostram uma forte associação entre o desenvolvimento das crianças e a qualidade do relacionamento marital com base em vários estudos com crianças cujas idades variavam da infância à adolescência. Além disso, um estudo sobre a qualidade das interações entre irmãos (Erel, Margolin \& John, 1998) revelou que o estabelecimento da qualidade de interações entre irmãos, em uma família, está associado à qualidade dos relacionamentos, tanto marital quanto parental. Enquanto os pesquisadores, durante os primeiros anos, procuraram intensivamente por variáveis únicas como aquelas responsáveis por diferentes trajetórias durante o desenvolvimento do indivíduo, os resultados de estudos observacionais mais recentes indicam que não é somente uma única variável, mas 
um conjunto de variáveis e condições relacionais mais complexas, que é o responsável pelos processos de desenvolvimento das crianças. Considerando os resultados disponíveis atualmente, parece que, à exceção das diferenças genéticas e de temperamento, não são os componentes únicos de padrões de interação, mas o conjunto de componentes variados, que pode ser relevante para as diferenças no curso de desenvolvimento da criança. Quando, por exemplo, os pais discutem freqüentemente um com o outro e são incapazes de achar uma solução comum para um problema, eles obviamente negligenciam um ao outro e não prestam atenção suficiente aos argumentos do parceiro. Neste clima, as crianças crescem em um tipo de cultura de comunicação que aparentemente não favorece aquelas que demandam mais autonomia e tentam negociar, com seus pais, mudanças em responsabilidades pessoais. Estas demandas e negociações são essenciais para o domínio bem sucedido da transição da infância para a adolescência. Além disso, os estudos que focalizam famílias divorciadas também têm mostrado que não é um componente único, mas o conjunto de várias condições, incluindo tanto aspectos econômicos quanto interacionais, que pode ser o responsável pelas desvantagens das crianças provenientes de lares desfeitos (Hetherington, Bridges \& Insabella, 1998).

Em síntese, os observadores, assistindo as gravações de interações familiares e procurando por aspectos relevantes para o desenvolvimento futuro, podem freqüentemente encontrar o que chamamos de barreira da irrelevância. Sob uma perspectiva atual, as condições para superar até mesmo esta barreira parecem um pouco mais promissoras do que há duas décadas atrás. Aspectos como qualidade e mutualidade do relacionamento, tão complexos quanto eles possam parecer, são bons candidatos para abstrações que trazem consigo uma relevância no que diz respeito ao desenvolvimento. Sob uma perspectiva metodológico-observacional, parece possível avaliar a qualidade de um relacionamento, em qualquer ato de comunicação. Porém, ao procurarmos pela qualidade das relacões nas interações do dia-a-dia, devemos estar cientes do fato de que, em nossa cultura ocidental, em nossa maneira usual de classificar, tendemos a focalizar as pessoas e suas ações, suas intenções e motivos, e não os seus relacionamentos e suas respectivas qualidades. Além disso, mesmo tentando nos concentrar na descrição de relacionamentos, não em pessoas, torna-se difícil, às vezes, discutir com os outros as várias qualificações de um relacionamento porque, simplesmente, não estamos acostumados a especificar, apropriadamente, os relacionamentos usando palavras comuns ou conceitos, como é o caso quando falamos sobre pessoas.

\section{Produzindo Dados Relacionais I: Algumas Questões Teóricas, Metodológicas e Práticas}

\section{Fidedignidade}

Nas pesquisas sobre a primeira infância, uma grande quantidade de dados foi gerada através de registros de com- portamentos altamente visíveis como movimento do corpo, olhar e segurar. Entretanto, estes aspectos comportamentais raramente podiam ser associados, no desenvolvimento posterior da criança, aos efeitos de variáveis de ordem superior, como inteligência ou habilidade social. A validade evolutiva de comportamentos isolados (únicos) não pôde ser estabelecida. Um critério amplamente utilizado para avaliar a qualidade de classificações, independentemente de qualquer validação, foi, e ainda continua sendo, o grau de concordância entre dois observadores que observam a mesma situação e usam categorias predefinidas, denominado concordância entre observadores. Este procedimento é necessário para garantir, pelo menos, um grau mínimo de acordo entre os observadores no que tange ao uso aceitável de um conjunto de categorias predefinidas. Porém, um alto índice de concordância não garante que uma determinada classificação represente uma abstração adequada de um segmento relevante da realidade. Com situações inteiras preservadas em videoteipe, vários procedimentos alternativos são possíveis para se obter indicadores de aceitação de uma representação.

Uma seleção de categorias baseada somente no critério de concordância entre observadores corre o risco de tratar aqueles fenômenos como sendo relevantes. Tais fenômenos podem ser diferenciados facilmente por alguns observadores, embora possam não representar aspectos que sejam, de fato, interessantes do ponto de vista de uma questão teórica. As decisões que visam obter abstrações próprias da realidade, isto é, representações significativas de situações observadas, somente são possíveis após um exame minucioso do material preservado em videoteipe; às vezes, somente após extensas análises comparativas de observações longitudinais. A criação de categorias adequadas deve ser direcionada para a captura da diversidade e também da especificidade, isto é, para a riqueza total do fenômeno observado em uma situação. De acordo com a perspectiva acima, fica evidenciado que o critério de seleção de categorias não pode ser baseado, em primeiro lugar, na facilidade com que dois observadores concordam entre si, embora, no final, esta condição também deva ser encontrada. Se, por exemplo, o foco da observação for em rituais de interação mostrados por ambos os genitores em uma família, uma seleção prematura de categorias, baseada no critério de um alto índice de concordância entre observadores, aumentaria o risco de que somente as abstrações deste padrão complexo sobrevivessem, descrevendo, assim, comportamentos simples, mas, talvez irrelevantes. Deste modo, outras classificações que abarcassem uma conceituação mais sofisticada e orientada para o relacionamento, mas que precisassem de algumas elaborações mais refinadas de detalhes relevantes, poderiam ser rejeitadas. Portanto, a seleção de categorias orientada pela concordância entre observadores reduz, sem dúvida, uma realidade complexa, talvez, apenas a comportamentos muito triviais que não espelham aqueles aspectos que haviam sido os alvos iniciais do estudo. Baixos índices de concordância entre observadores podem ser analisados e discutidos e a escolha de categorias pode ser melhor adaptada ao "o que" os observadores podem perceber depois de um processo de instrução sensitivo. 
Às vezes, não é fácil decidir se as categorias são bem selecionadas e os observadores ignorantes, ou se as categorias são mal selecionadas, sem orientações diferenciais claras, e os observadores competentes, mas que não sabem lidar bem com categorias ambíguas. Assim, a escolha de categorias deve sempre ser um processo longo de interação entre os pesquisadores que planejam o estudo e aqueles que analisam as observações. Com a possibilidade de replicar a situação observada, um processo tão extenso torna-se, agora, possível.

\section{Conceitos e categorias}

Na psicologia do desenvolvimento, acreditava-se que as crianças eram passivas, somente reagindo a estimulações. Assim, quando as crianças eram observadas mesmo em interações com suas mães, os observadores categorizavam os comportamentos dos bebês que se adequavam bem às suas expectativas, isto é, as reações às estimulações das mães. Era preciso um conceito novo de atividades de bebês (Bell, 1968) para construir categorias que pudessem registrar as próprias atividades dos bebês que fossem direcionadas a estimular suas mães (ver, por exemplo, Sorce, Emde, Campos \& Klinnert, 1985; Tronick, 1989; Tronick \& Cohn, 1989). Como no caso do desenvolvimento de bebês, um crescente corpo de dados coletados em vários estudos, finalmente, mostrou a sensibilidade bastante precoce de crianças no que diz respeito aos relacionamentos sociais complexos e aos contextos de comunicação (ver Saarni, Mumme \& Campos, 1998). Os pesquisadores podem ter começado suas observações com conceitos que eram direcionados às mães e como elas influenciavam padrões de comportamentos em suas crianças, mas, a mente aberta para as experiências inesperadas que ocorriam durante as observações acabou revelando as capacidades e atividades das crianças. Assim, uma nova teoria sobre a competência de crianças pôde, finalmente, criar um conjunto de novas categorias que descrevessem as interações complexas entre mãe-criança. Esta abertura para novos aspectos e o adiamento deliberado na aplicação de categorias predeterminadas durante a realização das observações foi enfatizada, por exemplo, por pesquisadores da infância como Richards e Bernal (1972) e Trevarthen (1977), que descrevem as experiências de suas primeiras observações:

Nosso registro de categorias originou-se de nossas observações, ao invés de ser imposto por algumas posições predeterminadas. Primeiro, observamos sem fazer qualquer tentativa de registrar. Depois, começamos a anotar as características de comportamento que se repetiam regularmente. (Richards \& Bernal, 1972, p. 181)

Eu evitei análises quantitativas até que os padrões de ação se tornaram claros. (Trevarthen, 1977, p. 9)

Historicamente, esta mudança do conceito de uma criança passiva para uma ativa e competente começou durante o início dos anos setenta, época em que a abertura em pesquisa observacional mencionada acima emergiu. Os biólo- gos e etólogos começaram a observar as interações mãe-criança focalizando aspectos mais dinâmicos e holísticos. Eles construíram um novo arcabouço de conceitos e categorias, tais como intenção ou intersubjetividade, com base nas habilidades específicas de uma dada espécie. Nas interações entre pais e crianças, constituem exemplos de tal extensão de categorias, o registro do comportamento de aconchego entre mães e seus bebês (Papoušek \& Papoušek, 1977), ou engajamento na dança para encontrar um rítmo comum (Stern, 1977). Cowan e Cowan (1987) propuseram um conceito interativo mais complexo ainda para ser observado nas interações entre os pais, após o nascimento de seu primeiro filho, a gavota parental, um padrão de empurra e puxa, caracterizando uma dança de pais e mães jovens para promover um entrosamento com o novo membro da família e mesmo entre si. Outro exemplo de tal mudança para categorias de interação mais complexas e descritivas pode ser encontrado nos trabalhos de Patterson (1979, 1986; Patterson \& Capaldi, 1991) iniciados com um arcabouço comportamental muito diferenciado e microanálises de comportamentos isolados (únicos) e finalizaram com um foco em unidades mais molares para a descrição de interação e processos de transmissão na família. Mutualidade, interrupção, correção de mal-entendidos, ou sinais de ignorar os outros eram conceitos novos, baseados, por sua vez, em conceitos mais holísticos de interação e comunicação humana.

\section{Perigo da reificação}

Sem uma ligação sistemática entre conceito e categoria e sem uma adaptação de categorias às situações concretas de observação, o uso formalizado ou mesmo padronizado de classificações pode desviar-se da intenção inicial de uma abstração significativa e, também, pode se tornar um perigo para observações exploratórias futuras. A reificação de categorias pode cegar um observador para novos fenômenos que podem surgir durante a observação e que são ignorados porque eles não se adequam ao conjunto de categorias selecionadas. Dewey (1922) foi um dos poucos a relacionar as dificuldades de reificação das categorias que foram deliberadamente selecionadas para classificar ações e reações humanas. Reificação significa que o aspecto funcional de descrever fenômenos complexos fazendo algumas abstrações do concreto não é mais levado em consideração. Como conseqüência, as abstrações para elaborar categorias não são mais vistas como escolhas intencionais e tentativas de representar a realidade, mas, ao contrário, a classificação abstrata se torna, ela mesma, uma ferramenta para explicar a realidade.

\footnotetext{
Classificar é, certamente, tão útil quanto natural. Uma variedade indefinida de eventos particulares e mutáveis é encontrada pela mente por meio de atos de definir, relacionar e listar, reduzindo-os a eventos similares e agrupados. Mas estes atos, como outros atos inteligentes, são realizados com um objetivo, e a realização deste objetivo é a sua única justificativa. De um modo geral, o objetivo é facilitar nossos modos de lidar com eventos únicos, individuais e mutáveis. Quando assumimos que
} 
nossos agrupamentos e divisões representam, respectivamente, agrupamentos organizados naturalmente e separações fixas, obstruímos ao invés de ajudar nossas transações com as coisas. Somos culpados de uma presunção que a natureza pune imediatamente. Somos uns rendidos incompetentes para lidar eficazmente com as sutilezas e novidades da natureza e da vida. Nosso pensamento é limitado, quando os fatos são dinâmicos; atados e pesados, quando os eventos são fluidos, dispersos. (Dewey, 1922, pp. 131-132)

Este enfoque inadequado para as abstrações, ressaltado por Dewey em seu exemplo de reificação de instintos, às vezes parece ter sobrevivido nos debates contemporâneos sobre metodologia observacional. Para evitar o perigo destes tipos de reificação, a observação aberta de comportamentos em seu contexto pode fornecer alguma ajuda, particularmente quando a observação visa não somente a descrição da superfície do fenômeno, mas também a descoberta de padrões recorrentes e estruturas de comportamentos, em sua profundidade.

\section{Produzindo Dados Relacionais II: Propostas para Aplicações Ampliadas}

\section{Novas categorias para padrões de relacionamento complexos em constelações triádicas}

Dados observacionais que descrevem duas pessoas interagindo necessitam de categorias que abarquem as dinâmicas de relacionamento entre estas duas pessoas. Historicamente, a análise Lag de Sackett (1979) e a análise seriada no tempo de Gottman (1979), incluindo aspectos da teoria da informação (Gottman \& Bakeman, 1979), constituem o marco inicial das tentativas para se obter um insight dos processos dinâmicos durante interações. Porém, estas análises eram, em sua maioria, restritas às interações diádicas. As famílias são compostas de mais de duas pessoas, pelo menos três. Dois genitores e uma criança formam uma constelação triádica com duas relações intergeracionais pais-criança, além da relação marital entre os pais. Assim, assume-se que as situações triádicas, com ambos os genitores e a criança, representam uma situação de interação típica em uma família. A transmissão intergeracional e interparental ocorre simultaneamente e a participação das crianças na comunicação pai-mãe pode revelar suas experiências específicas dentro da rede de relações complexas na família. Estas experiências não podem ser propriamente descritas por observações de díades famíliares (Cowan \& McHale, 1996).

As categorizações de comportamento relacional de ordem superior podem ser muito promissoras se, e somente se, estes aspectos forem descritos abarcando o efeito real de relações de ordem superior e não somente replicando aspectos isolados ou diádicos da comunicação. Em nossa tentativa de desenvolver um sistema triádico de categorias (Ullrich \& Kreppner, 1999), não focalizamos a comparação de constelações diádicas com triádicas, conforme enfatizado, por exemplo, em estudos conduzidos por Deal e seus colaboradores (Deal, Hagan, Bass, Hetherington \& Clingempeel,
1999). Ao invés disto, tentamos elaborar as dinâmicas específicas desenvolvidas somente em uma constelação triádica e que não eram vistas em constelações diádicas. A criança não pode ver o relacionamento entre os pais, enquanto estes atuam na vida, quando ela está em uma situação diádica com um dos pais. Em uma tríade, a criança pode experienciar, particulamente, padrões de comportamento complexos como integração ou exclusão de uma terceira pessoa, lealdade ou coalizão, competição ou ciúme. Quando ambos os pais estão presentes em uma tríade, a criança pode observar as dinâmicas do relacionamento parental, por exemplo, como a mãe e o pai lidam com opiniões opostas etc. A criança reage a uma comunicação interparental, que pode também ser vista por ela somente em uma constelação triádica, e nunca em uma díade mãe-criança ou pai-criança. Este tipo de dinâmica específico de uma tríade, que é muito diferente do que se desenvolve em um relacionamento diádico, foi explicado sob uma perspectiva mais formal por Kelley e Thibaut (1978) e, posteriormente, elaborada como sendo importante para as trajetórias de desenvolvimento individual por McHale e Rasmussen (1998). Por exemplo, a ansiedade crescente de crianças aos 3-4 anos de idade foi predita pelo aumento dos comportamentos de distanciamento dos pais quando a criança tinha 11 meses de idade. Do mesmo modo, o nível de agressão era maior em crianças quando comportamentos competitivos-agressivos e baixa harmonia foram encontrados na tríade mãe-pai-criança. Novos aspectos formais das dinâmicas triádicas foram observados em estudos mais recentes e relatados como sendo importantes quando focalizavam dinâmicas da constelação triádica (Jory, Rainbold, Karns, Freeborn \& Greer, 1996) como trocas específicas dirigidas (ex.: da mãe à criança e desta ao pai ou da criança à mãe e desta ao pai), ou rituais de exclusão (ex.: um membro é tratado pelos outros dois como um estranho (Bowen, 1976). Outro novo enfoque pode ser visto na tentativa de McHale (1995) para medir as dinâmicas de comunicação em tríades. Ele introduziu variáveis como orientação da criança versus orientação dos pais ou apoio mútuo, ou, ainda, intervenção agressiva excluindo um membro.

Em resumo, apesar de os pesquisadores serem confrontados com uma complexidade imensa em uma tríade, a observação intensa desta constelação tem contribuído para criar um número de novas categorias que, agora, descrevem condições interativas muito mais diretamente do que quando somente os comportamentos isolados serviam de base para categorizações.

\section{Enfoques produtivos e reprodutivos em pesquisa observacional}

Desde que os observadores começaram a usar as técnicas de filme ou vídeo para preservar o que observavam, enfoques bastante inovativos para gerar categorias visando a obtenção de dados tornaram-se possíveis. Estas categorias são um tanto diferentes daquelas que foram construídas quando os dados tinham que ser produzidos no momento em que ocorriam, durante a observação. Thiel (1991) introduziu a 
noção de enfoque reprodutivo e produtivo. Um enfoque reprodutivo faz uso considerável do fato de que a situação completa está gravada em videoteipe e pode ser reconstruída pela observação cuidadosa e repetida da fita, pela análise dos movimentos em câmera lenta e pela transcrição das expressões verbais. Este processo recorrente-reflexivo inicia uma interpretação do material observado (uma situação social com interações mais ou menos complexas e manipulações de comunicação dos participantes observados) que, depois de algumas comparações com base no cruzamento de uma situação com outras situações, conduz a uma análise profunda do fenômeno observado. Este enfoque reprodutivo pode levar, no final, a uma interpretação da estrutura profunda de um conjunto de padrões de comportamentos recorrentes, como foi proposto por Kurt Lewin (1927). Tal procedimento implica adotar uma nova compreensão de diversas formas e seqüências de padrões de comportamento que ocorrem em uma dada situação. Portanto, o foco mudou de uma descrição de elementos de comportamentos isolados para a aquisição de conhecimento sobre processos que podem gerar estes comportamentos isolados.

Uma transcrição precisa de um episódio pode favorecer o enfoque reprodutivo. Ela demanda uma reconstrução altamente intensa das interconexões de comportamentos verbais, gestos, expressões faciais e movimentos corporais que, por sua vez, apoiam o processo recorrente-reflexivo. A fim de produzir uma interpretação coerente do episódio, os componentes que foram previamente ou ignorados ou considerados triviais podem ser incluídos. O objetivo deste procedimento, então, não é o agrupamento de mais e mais sequiências comportamentais, mas a compreensão dos processos básicos que geram as seqüências de comportamentos observados.

Uma outra maneira de lidar com material de observação surge quando uma técnica de vídeo moderna é empregada. É o enfoque produtivo, que aplica técnicas cinematográficas avançadas visando revelar novos aspectos que estão possivelmente obscuros ou mesmo escondidos em uma situação particular. Tais aspectos só podem emergir quando, por exemplo, os materiais são colocados juntos em uma nova fita, mostrando a mesma pessoa em diferentes situações e, talvez, até mesmo, em diferentes períodos de desenvolvimento. Esta condensação intencional dos comportamentos de uma pessoa em diferentes situações e períodos evolutivos pode gerar novos insights sobre a estabilidade, no tempo, dos chamados padrões recorrentes típicos. Assim, a nova montagem de material de vídeo proveniente de diferentes observações pode ajudar a produzir formatos completos, descrevendo comportamentos similares em uma pessoa e seus modos de interagir com outras pessoas. Além disto, esta técnica pode também contribuir para criar novas tipificações dos comportamentos observados. De acordo com Gesell (1928, 1935),

A documentação fotográfica deve ser concebida de tal maneira a preservar seqüências significativas. $O$ desenvolvimento é difícil de ser descrito porque está sempre mudando. O processo de mudança é tão subtil que não pode ser apreendido por julgamentos instantâneos. Portanto, podemos recorrer a este terceiro olho, o olho registrador da câmera, para capturar o que é difícil de ser descrito; para trazer o passado, o presente e o futuro juntos, em um compasso próximo. A função da câmera é diminuir os efeitos prolongados da idade cronológica para que as seqüencias de crescimento possam ser vislumbradas em uma justaposição espacial sem o tédio acarretado pelo longo espaço de tempo. Com estes princípios presentes em mente, nos comprometemos a desenvolver certas possibilidades de fotografia no estudo genético da infância. (Gesell, 1928, pp. 56-57)

A vantagem de usar técnicas de montagem para a criação de categorias ainda é amplamente ignorada, embora não haja dúvidas de que este enfoque poderia ser muito útil para a comparação de gravações longitudinais. Ele poderia trazer uma nova perspectiva na busca por indicadores relevantes em processos de desenvolvimento individual. Infelizmente, muitos pesquisadores contemporâneos parecem, aparentemente, categorizar o que eles observam e preservam instantaneamente em videoteipe como se tivessem que classificar durante a observação, ou seja, uma vez e para sempre. As técnicas de observação estão sendo debatidas, mesmo após setenta anos da disponibilidade de técnicas de gravação em filme, de uma maneira como se somente o método de observação direta existisse. Nossa longa história de uso de técnicas de filmagem para explorar o desenvolvimento, manifestas, por exemplo, nas obras de Gesell e de Lewin, parece quase esquecida.

\section{Criação de novas classes de variáveis descrevendo interações e relacionamentos}

Mesmo nos dias de hoje, a maioria dos estudos que utiliza métodos observacionais ainda está coletando dados somente de comportamentos isolados, quando as técnicas de observação moderna, incluindo equipamentos de edição avançados, podem oferecer enfoques mais ricos para a coleta de dados e uma gama maior de oportunidades para analisar padrões complexos de relacionamento ou mudanças no desenvolvimento. É evidente que aspectos como mutualidade, fluxo de comunicação e regulação de emoções em um relacionamento necessitariam de uma mudança no foco de atenção dos observadores, de comportamentos isolados para interações, e também de uma mudança nos planejamentos de pesquisa no sentido de criar situações complexas para que os sujeitos sejam observados. Da mesma forma, os conceitos orientados para as interações/relações também requerem ambientes novos e mais complexos para a condução das observações. Gerando novas classes de variáveis, poderemos, com esperança, ficar um pouco mais próximos à demanda de Lewin (1927) para revelar as conexões genéticas-condicionais entre os padrões de comportamento visíveis na superfície e suas dinâmicas relacionais básicas, responsáveis por suas ocorrências repetidas. Estas variáveis devem ser capazes de descrever fenômenos interacionais mais complexos como o estabelecimento de significado comum em uma família através de conselho, calor humano e ordens. Entretan- 
to, para lidar com um conceito que categoriza a qualidade de trocas significativas em um relacionamento, precisaríamos adicionar um número de referências, seja para as representações internas dos sujeitos, seja para os outros fenômenos observáveis porque, por exemplo, o estabelecimento de significado comum em um relacionamento não pode ser diretamente observado. O que pode ser observado, porém, são as trocas de emoções, o grau de adaptação subtil às intenções dos outros, a habilidade para corrigir mal-entendidos e assim por diante. Por exemplo, Spitz (1964) enfatizou em seu trabalho o papel do afeto para a construção de significado no relacionamento mãe-criança. A concretização do significado é conectada a um afeto positivo, o final positivo de um ciclo de ação em um diálogo. Se este ciclo é interrompido e o significado não pode ser concretizado, então, nos termos de Spitz, o diálogo entre a mãe e o bebê "desvia-se da rota". Do mesmo modo, Sroufe (1996) tem destacado o papel da emoção como um princípio organizador a partir da construção de significado na infância precoce. Como muitos estudos observacionais na pesquisa em desenvolvimento ainda continuam coletando somente unidades comportamentais desconectadas, um esforço mais intenso para criar novas classes de variáveis, espelhando as dinâmicas de trocas emocionais e cognitivas em um relacionamento, poderia ser muito útil para obter informações sobre as estruturas alternativas profundas das duas trajetórias de desenvolvimento que conduzem a uma compreensão da capacidade do indivíduo para estabelecer relacionamentos bem ou mal sucedidos.

\section{Comentários Conclusivos}

Este artigo é a revisão de um trabalho escrito aproximadamente há duas décadas visando a discussão de problemas associados à aplicação de métodos observacionais. Desde então, um longo período de tempo transcorreu e um imenso progresso técnico mudou, dramaticamente, as condições da pesquisa observacional. A reflexão sobre as continuidades e mudanças durante este longo período, lendo o texto antigo, produziu três resultados principais. Primeiro, o método de observação certamente ganhou mais aceitação e reputação comparado ao passado, particularmente na pesquisa em desenvolvimento infantil. Segundo, técnicas de observação avançadas são usadas por mais e mais pesquisadores. Porém, paradoxalmente, as análises e avaliações das situações observadas que foram preservadas em videoteipe ainda são realizadas de uma maneira, como se elas estivessem sob as restrições da observação direta, sem a preservação em vídeo. Terceiro, constatou-se que a maioria das questões fundamentais associadas ao método de observação não foi mais discutida durante as duas últimas décadas, apesar deste método ter sido amplamente usado, principalmente na pesquisa com crianças. Eu tentei abordar algumas questões relativas à como encontrar representações próprias, como superar barreiras básicas que podem dificultar o trabalho dos observadores e como os enfoques reprodutivos e produtivos podem ser usados para lidar com material observacional. As idéias interrompidas sobre os possíveis ganhos de se usar a observação como um método, conforme discutido há muito tempo atrás por Lewin e por Gesell, parecem quase perdidas. Muitas das questões e, também, das respostas dadas por estes pesquisadores poderiam estar, talvez, mais presentes nas discussões metodológicas contemporâneas, se um uso mais sofisticado de recursos observacionais, como técnicas de vídeo e processamento eletrônico, fosse seriamente considerado. Hoje, com as novas possibilidades de trabalhar com material de vídeo de uma maneira semelhante à que estamos acostumados a trabalhar com nossos textos no computador, temos que assumir a tarefa de dirigir a metodologia observacional a um ponto onde algo como estruturas profundas, que geram os fenômenos de superfície rotulados por Lewin como conexões genéticas-condicionais, poderiam ser reveladas, ou onde, com a ajuda das idéias de Gesell sobre o uso de técnicas de montagem, novos insights do processo de desenvolvimento poderiam ser criados. Revisando os estudos observacionais na área de desenvolvimento, que utilizam os recursos avançados das técnicas de vídeo, ainda encontramos muitos planejamentos de pesquisa tradicionais cujo foco são as variáveis únicas e as análises lineares de causa e efeito. A riqueza da interação humana, com toda a sua complexidade, poderia ser conservada em muitas fitas, mas somente uma nova forma de analisá-la, usando novos conceitos, possibilitaria avançar um passo adiante.

\section{Referências}

Bell, R.Q. (1968). A reinterpretation of the direction of effects in studies of socialization. Psychological Review, 75, 81-95.

Bowen, M. (1976). Theory on practice of psychotherapy. Em P.J. Guerin (Org.), Family therapy (pp. 337-388). New York: Gardner Press.

Cowan, C.P. \& Cowan, P.A. (1987). Men's involvement in parenthood: Identifying the antecedents and understanding the barriers. Em P.W. Berman \& F.A. Pedersen (Orgs.), Men's transition to parenthood (pp. 145-174). Hillsdale, NJ: Lawrence Erlbaum.

Cowan, P.A. \& Mc Hale, J.P. (1996). Coparenting in a family context: Emerging achievements, current dilemmas, and future directions. Em W. Damon (Org. da Série), J.P. McHale \& P.A. Cowan (Org. do Vol.), New Directions for Child Development: Vol. 74. Understanding how family-level dynamics affect children's development: Studies of two-parent families (pp. 93106). San Francisco: Jossey Bass.

Deal, J.E., Hagan, M.S., Bass, B., Hetherington, E.M. \& Clingempeel, G. (1999). Marital interaction in dyadic and triadic contexts: Continuities and discontinuities. Family Process, $38,105-115$.

Dewey, J. (1922). Human nature and conduct. An introduction to social psychology. New York: Henry Holt and Company.

Erel, O. \& Burman, B. (1995). Interrelatedness of marital and parent-child relations: A meta-analytic review. Psychological Bulletin, 118, 108-132.

Erel, O., Margolin, G. \& John, R.S. (1998). Observed sibling interaction: Links with the marital and the mother-child relationship. Developmental Psychology, 34, 288-298. 
Gesell, A. (1928). Infancy and human growth. New York: MacMillan Company.

Gesell, A. (1935). Cinemanalysis: A method of behavior study. Journal of Genetic Psychology, 47, 3-16.

Gottman, J.M. (1979). Time-series analysis of continuous data in dyads. Em M.E. Lamb, S.J. Suomi \& G.R. Stephenson (Orgs.), Social interaction analysis (pp. 207-226). Madison: University of Wisconsin Press.

Gottman, J.M. \& Bakeman, R. (1979). The sequential analysis of observational data. Em M.E. Lamb, S.J. Suomi \& G.R. Stephenson (Orgs.), Social interaction analysis (pp. 185-206). Madison: University of Wisconsin Press.

Hetherington, E.M., Bridges, M. \& Insabella, G.M. (1998). What matters? What does not? Five perspectives on the association between marital transitions and children's adjustment. American Psychologist, 53, 167-184.

Jory, B., Rainbolt, E., Karns, J.T., Freeborn, A. \& Greer, C.V. (1996). Communication patterns and alliances between parents and adolescents during a structured problem-solving task. Journal of Adolescence, 19, 339-346.

Kelley, H.H. \& Thibaut, J.W. (1978). Interpersonal relations. A theory of interdependence. New York: Wiley.

Kreppner, K. (1982). Zur interpretation von alltagshandeln in der familie: Drei barrieren vor dem erkennen? [On the interpretation of everyday behavior in the family: Three barriers before knowledge?]. Contribution to the discussion group "Experiences with non-standardized research methods" at the 33th Conference of the German Society for Psychology, Mainz, Germany.

Kreppner, K. (1991). Observation and the longitudinal approach in infancy research. Em M. Lamb \& H. Keller (Orgs.), Infant development: Perspectives from German-speaking countries (pp. 151-178). Hillsdale, NJ: Lawrence Erlbaum.

Kreppner, K., Paulsen, S. \& Schütze, Y. (1981). Familiale dynamik und sozialisatorische interaktion nach der geburt des zweiten kindes [Family dynamics and socialisation interaction after birth of the second child]. Zeitschrift für Sozialisationsforschung und Erziehungsstile, 1, 291-297.

Kreppner, K., Paulsen, S. \& Schütze, Y. (1982a). Infant and family development: From triads to tetrads. Human Development, 25, 373-391.

Kreppner, K., Paulsen, S. \& Schütze, Y. (1982b). Kindliche entwicklung und familienstruktur [Child development and family structure]. Zeitschrift für Pädagogik, 28, 221-244.

Lewin, K. (1927). Gesetz und experiment in der Psychologie [Law and experiment in psychology]. Symposion, 1, 375-421.

McHale, J.P. (1995). Coparenting and triadic interactions during infancy: The roles of marital distress and child gender. Developmental Psychology, 31, 985-996.

McHale, J.P. \& Rasmussen, J.L. (1998). Coparental and family group-level dynamics during infancy: Early family precursors of child and family functioning during preschool. Development and Psychopathology, 10, 39-59.

Papoušek, H. \& Papoušek, M. (1977). Mothering and the cognitive head-start: Psychobiological considerations. Em H.R. Schaffer (Org.), Studies in mother-infant interaction (pp. 6385). New York: Academic Press.

Patterson, G.R. (1979). A performance theory for coercive family interaction. Em R.B. Cairns (Org.), The analysis of social interaction (pp. 119-162). Hillsdale, NJ: Erlbaum.
Patterson, G.R. (1986). Performance models for antisocial boys. American Psychologist, 41, 432-444.

Patterson, G.R. \& Capaldi, D.M. (1991). Antisocial parents: Unskilled and vulnerable. Em P.A. Cowan \& M. Hetherington (Orgs.), Family transitions (pp. 195-218). Hillsdale, NJ: Lawrence Erlbaum.

Richards, M.P.M. \& Bernal, J.F. (1972). An observational study of mother-infant interaction. Em N. Blurton-Jones (Org.), Ethological studies of child behaviour (pp. 175-197). Cambridge: Cambridge University Press.

Rosenthal, R. (1966). Experimenter effects in behavioral research. New York: Appleton Century Crofts.

Saarni, C., Mumme, D.L. \& Campos, J. (1998). Emotional development: Action, communication, and understanding. Em W. Damon (Org. da Série.) \& N. Eisenberg (Org. do Vol.), Handbook of Child Psychology: Vol. 3. Social, emotional, and personality development ( $5^{\text {a }}$ ed., pp. 237-309). New York: Wiley.

Sackett, G.P. (1979). The lag sequential analysis of contingency and cyclicity in behavioral interaction research. Em J.D. Osofsky (Org.), Handbook of infant development (pp. 623-649). New York: Wiley.

Sorce, J.F., Emde, R.N., Campos, J. \& Klinnert, M.D. (1985). Maternal emotional signaling: Its effect on the visual cliff behavior of 1-year-olds. Developmental Psychology, 21, 195-200.

Spitz, R. (1964). The derailment of dialogue: Stimulus overload, action cycles, and the completion gradient. Journal of the American Psychoanalytic Association, 12, 752-770.

Sroufe, L.A. (1996). Emotional development. The organization of emotional life in the early years. New York: Cambridge University Press.

Stern, D.N. (1977). The first relationship. Infant and mother. London: Open Books.

Suppes, P. \& Zinnes, J.L. (1963). Basic measurement theory. Em R.D. Luce, R.R. Bush \& E. Galanter (Orgs.), Handbook of mathematical psychology (pp. 1-16). New York: Wiley.

Thiel, T. (1991). Videotechnique and science: Methodological considerations. Em M. Lamb \& H. Keller (Orgs.), Infant development: Perspectives from German-speaking countries (pp. 179195). Hillsdale, NJ: Lawrence Erlbaum.

Trevarthen, C. (1977, October). Instincts for human understanding and for cultural cooperation: Their development in infancy. Paper presented at the Werner-Reimer-Stiftung Symposium on Human Ethology, Bad Homburg, Germany.

Tronick, E.Z. (1989). Emotions and emotional communication in infants. American Psychologist, 44, 112-119.

Tronick, E.Z. \& Cohn, J. (1989). Infant-mother face-to-face interaction: Age and gender differences in coordination and the occurrence of miscoordination. Child Development, 60, 85-91.

Ullrich, M. \& Kreppner, K. (1999, September). Kommunikation in eltern-kind triaden mit jugendlichen: Entwicklung eines kategoriensystems [Communication in parent-child triads with adolescents. Development of a category system]. Paper presented at the fourteenth Meeting of the Division of Developmental Psychology in the German Psychological Society, Fribourg, Schwitzerland. 